\title{
The salivary protein BPIFA2 differentially regulates sodium preference and blood pressure in male and female mice
}

\author{
Sven-Ulrik Gorr \\ Department of Diagnostic and Biological Sciences, University of Minnesota School of Dentistry, Minneapolis Minnesota, U.S.A.
}

(Received 08 May 2020; Revised 24 May 2020; Accepted 25 May 2020)

\begin{abstract}
BPIFA2 (PSP, SPLUNC2, C20orf70) is a major salivary protein of uncertain physiological function. BPIFA2 is downregulated in salivary glands of spontaneously hypertensive rats, pointing to a role in blood pressure regulation. This study used a novel Bpifa2 knockout mouse model to test the role of BPIFA2 in sodium preference and blood pressure. Blood pressure did not differ between wild-type male and female mice but was significantly lower in male knockout mice compared to male wild-type mice. In contrast, blood pressure was increased in female knockout mice compared to female wild-type mice. Female wild-type mice showed a significant preference for $0.9 \%$ saline compared to male mice. This difference was reduced in the knockout mice. BPIFA2 is an LPS-binding protein but it remains to be determined if the reported effects are mediated by the LPS-binding activity of BPIFA2.
\end{abstract}

Keywords: Saliva; SPLUNC2; hypertension; sodium intake

\section{Introduction}

BPIFA2 (BPI fold-containing family A, member 2) (previously named Parotid Secretory Protein - PSP, SPLUNC2, C20orf70) is an abundant protein in mouse saliva (Nandula et al., in press) and Bpifa2 is highly expressed in the three paired major salivary glands (Gao et al., 2018). BPIFA2 is structurally related to LPS-binding proteins and the salivary protein binds LPS and contains an LPS-blocking peptide (Abdolhosseini et al., 2012). Indeed, we recently characterized a Bpifa2 knockout mouse and found that BPIFA2 is the major surfactant protein in mouse saliva and BPIFA2 depletion affects the activity of ingested LPS, insulin secretion and the metabolomics profile (Nandula et al., in press). Our recent report left a number of alternate functions for BPIFA2 unexplored. In this report we show that BPIFA2 may also play a role in sodium intake and blood pressure regulation.

\section{Objective}

The physiological function of BPIFA2 remains uncertain but the protein is down-regulated 6-fold in male spontaneously hypertensive rats compared to normotensive WKY rats (Zhang et al., 2017). The objective of this study was to determine if BPIFA2 expression affects blood pressure in a Bpifa2 knockout mouse model. Since sodium intake is associated with hypertension, the study also determined the effect of BPIFA2 depletion on sodium preference in this mouse model.

\footnotetext{
(c) The Author(s) 2020. This is an Open Access article, distributed under the terms of the Creative Commons Attribution licence (http:// creativecommons.org/licenses/by/4.0/), which permits unrestricted re-use, distribution, and reproduction in any medium, provided the original work is properly cited.
} 

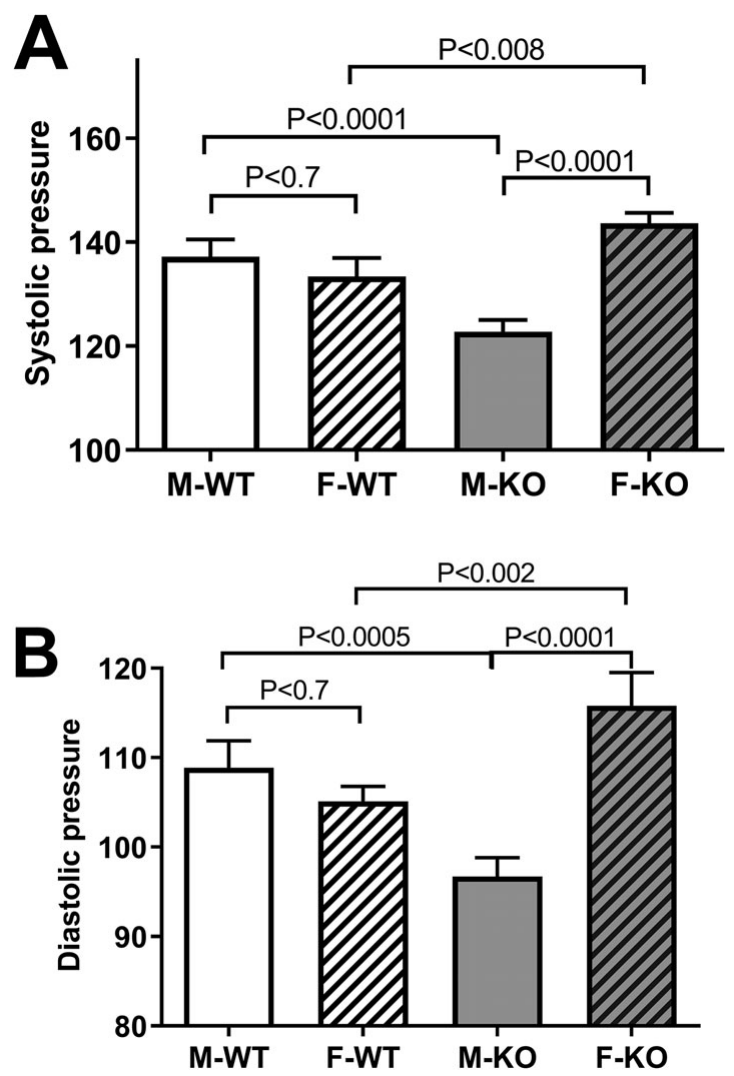

Figure 1. Blood pressure. A. systolic BP in Male (M) and Female (F), WT and KO mice. Six mice per group, 13-18 readings/ mouse, $N=79-107$. B. diastolic BP in the same groups as in panel A. Data are shown as mean $\pm 95 \%$ confidence intervals. The groups were compared by one-way ANOVA with Sidaks post-test for multiple comparisons.

\section{Methods}

\section{Mouse colony}

Animal experiments were reviewed and approved by the University of Minnesota Institutional Animal Care and Use Committee. The authors assert that all procedures contributing to this work comply with the ethical standards of the relevant national and institutional guides on the care and use of laboratory animals. Bpifa2 ${ }^{\text {tm1(KOMP)Vlcg }}$ (RRID: MMRRC_046819-UCD) were obtained from the KnockOut Mouse Project at UC Davis (https://www.komp.org/) and bred and housed as described (Nandula et al., in press). Different groups of mice were used for the blood pressure and sodium preference experiments.

\section{Blood pressure and heart rate monitoring}

Mice were acclimatized in the CODA system (Kent scientific, Torringtron, CT) for 3 days prior to experiments. Blood pressure was monitored in 6 mice per group with a tail cuff. Each mouse was tested for up to 23 cycles and data cycles accepted as defined by the instrument. Heart rate was monitored simultaneously with blood pressure.

\section{Sodium intake}

Mice (18 males per group; 8 females per group) were acclimatized to two water bottles with free access to food. The mice were then provided one bottle with pure water and one bottle that contained $0.15 \mathrm{M} \mathrm{NaCl}$. Consumption from both bottles was calculated after 3 days at which time their position was switched and 


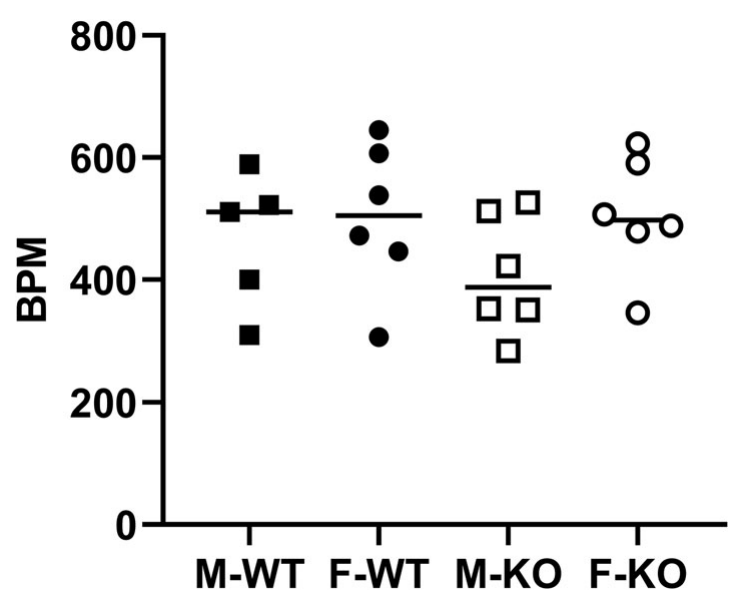

Figure 2. Heart rates. Heart rates (BPM) were recorded during the blood pressure determination in the same groups as in Fig. 1. Each point represents one mouse. Data were analyzed by one-way ANOVA with Tukey's multiple comparisons post-test. $P>0.4$ for all pairwise comparisons.

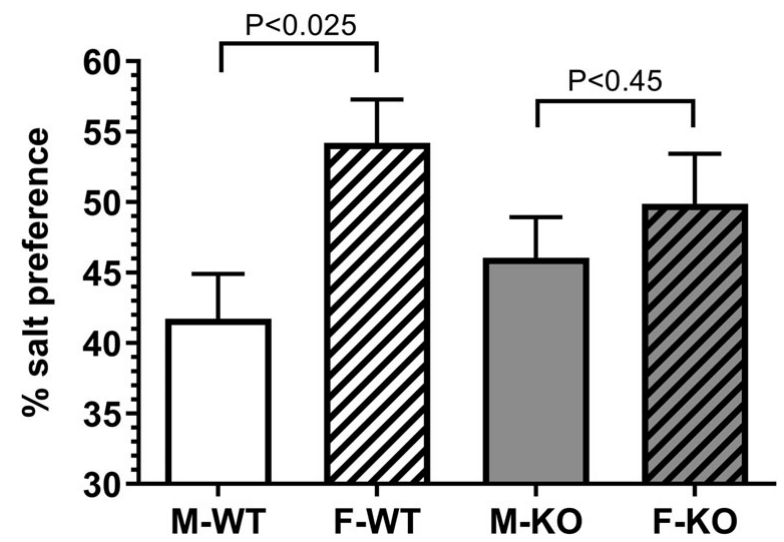

Figure 3. Sodium preference. The preference for $0.15 \mathrm{M} \mathrm{NaCl}$ was determined in duplicate by two-bottle cross-over test against pure water. $\mathrm{N}=18(\mathrm{M}), \mathrm{N}=8(\mathrm{~F})$. Data are shown as mean $\pm 95 \% \mathrm{Cl}$ and were analyzed by Student's t-test for each genotype. P-values are shown.

consumption again calculated after 3 days. \% salt preference was calculated as ( $\mathrm{ml}$ salt water consumed / total water consumption) $\mathrm{x} 100 \%$.

\section{Results}

BPIFA2 differentially alters blood pressure in male and female mice

To test the effect of BPIFA2 on BP, this was monitored in groups of mice and compared between male and female, WT and KO mice. Systolic (Fig. 1A) and diastolic (Fig. 1B) BP did not differ between WT male and female mice. However, both readings were significantly lower in male $\mathrm{KO}$ mice compared to male WT mice. In contrast, BP was increased in female KO compared to both female WT mice and male KO mice (Fig. 1). The heart rate did not differ between experimental groups (Fig. 2).

\section{BPIFA2 differentially alters salt preference in male and female mice}

Female WT mice showed a significant preference for $0.9 \%$ saline compared to male WT mice. This difference was reduced in the absence of BPIFA2, suggesting that this protein affects sodium preference (Fig. 3). 


\section{Discussion}

Depletion of BPIFA2 leads to decreased blood pressure in male mice. Thus, the decreased BPIFA2 expression reported in male hypertensive rats (Zhang et al., 2017) may be a compensatory response to the higher blood pressure in these rats. The reverse effect of BPIFA2 depletion in female mice suggests that the effect of BPIFA2 is sex dependent.

\section{Conclusions}

We previously reported that BPIFA2 binds LPS (Abdolhosseini et al., 2012) and affects the activity of ingested LPS and metabolic endotoxemia (Nandula et al., in press). In addition, renal stem/progenitor cells respond to an LPS insult by secretion of BPIFA2 (Sallustio et al., 2019). The results presented here expand the systemic effects to sodium intake and blood pressure control. It remains to be determined if these effects are mediated by BPIFA2 binding of oral LPS. The oral microbiome is a source of oral LPS, which could affect blood pressure and sodium intake. In this context, the recent finding that changes in the oral microbiome are linked to hypertension in post-menopausal women (Gordon et al., 2019) suggests an effect of sex hormones on oral LPS levels, which could mediate the observed effects on blood pressure. LPS also regulates epithelial sodium channels (Baines et al., 2010), which have been implicated in sodium preference (Roper, 2015) and are regulated by BPIFA2 (Tarran et al., 2012). The results presented here point to a novel pathway for blood pressure regulation that originates in the oral cavity.

Acknowledgements. I thank Dr. Pilar Ariza Guzmán, University of Minnesota Integrative Biology and Physiology Phenotyping Cores and the staff of the University of Minnesota Research Animal Resources for assistance with the blood pressure experiments and mouse colony husbandry, respectively.

Author Contributions. SUG conceived and designed the study, conducted data gathering, performed statistical analyses and wrote the article.

Funding Information. This work was supported by research funds from the University of Minnesota School of Dentistry, which is gratefully acknowledged. No other specific grant from any funding agency, commercial or not-for-profit sectors were received for this research.

Conflicts of Interest. The author declares no conflicts of interest.

Data Availability Statements. Raw data files are available from the author upon request, subject to institutional approval.

\section{References}

Abdolhosseini, M., Sotsky, J. B., Shelar, A. P., Joyce, P. B., \& Gorr, S. U. (2012). Human parotid secretory protein is a lipopolysaccharide-binding protein: Identification of an anti-inflammatory peptide domain. Molecular and Cellular Biochemistry, 359, 1-8. doi:https://doi.org/10.1007/s11010-011-0991-2.

Baines, D. L., Albert, A. P., Hazell, M. J., Gambling, L., Woollhead, A. M., \& Dockrell, M. E. C. (2010). Lipopolysaccharide modifies amiloride-sensitive $\mathrm{Na}+$ transport processes across human airway cells: Role of mitogen-activated protein kinases ERK 1/2 and 5. Pflugers Archiv: European Journal of Physiology, 459, 451-463. doi:https://doi.org/10.1007/s00424-0090717-4.

Gao, X., Oei, M. S., Ovitt, C. E., Sincan, M., \& Melvin, J. E. (2018). Transcriptional profiling reveals gland-specific differential expression in the three major salivary glands of the adult mouse. Physiological Genomics, 50, 263-271. doi:https://doi. org/10.1152/physiolgenomics.00124.2017.

Gordon, J. H., LaMonte, M. J., Genco, R. J., Zhao, J., Li, L., Hovey, K. M., Tsompana, M., Buck, M. J., Andrews, C. A., Mcskimming, D. I., Zheng, W., Sun, Y., \& Wactawski-Wende, J. (2019). Is the oral microbiome associated with blood pressure in older women?. High Blood Pressure \& Cardiovascular Prevention: The Official Journal of the Italian Society of Hypertension, 26, 217-225. doi:https://doi.org/10.1007/s40292-019-00322-8.

Nandula, S. R., Huxford, I., Wheeler, T. T., Aparicio, C., \& Gorr, S.-U. (in press). The parotid secretory protein BPIFA2 is a salivary surfactant that affects LPS action. Experimental Physiology. doi:https://doi.org/10.1113/EP088567.

Roper, S. D. (2015). The taste of table salt. Pflugers Archiv: European Journal of Physiology, 467, 457-463. doi:https://doi. org/10.1007/s00424-014-1683-Z.

Sallustio, F., Stasi, A., Curci, C., Divella, C., Picerno, A., Franzin, R., Palma, G. D., Rutigliano, M., Lucarelli, G., Battaglia, M., Staffieri, F., Crovace, A., Pertosa, G. B., Castellano, G., Gallone, A., \& Gesualdo, L. (2019). Renal progenitor cells 
revert LPS-induced endothelial-to-mesenchymal transition by secreting CXCL6, SAA4, and BPIFA2 antiseptic peptides. FASEB Journal, 33, 10753-10766. doi:https://doi.org/10.1096/fj.201900351R.

Tarran, R., Stutts, M. J., \& Donaldson, S. (2012). USA Patent https://patents.google.com/patent/EP2760463A1

Zhang, J., Zhong, L.-J., Wang, Y., Liu, L.-m., Cong, X., Xiang, R.-L., Wu, L.-L., Yu, G.-Y., \& Zhang, Y. (2017). Proteomic analysis reveals an impaired Ca2+/AQP5 pathway in the submandibular gland in hypertension. Scientific Reports, 7, 14524. doi:https://doi.org/10.1038/s41598-017-15211-0.

Cite this article: Gorr S-U (2020). The salivary protein BPIFA2 differentially regulates sodium preference and blood pressure in male and female mice Experimental Results, 1, e18, 1-9. https://doi.org/10.1017/exp.2020.23 


\section{Peer Reviews}

\section{Reviewing editor: Dr. Michael Nevels}

University of St Andrews, Biomolecular Sciences Building, Fife, United Kingdom of Great Britain and Northern Ireland, KY16 9ST

This article has been accepted because it is deemed to be scientifically sound, has the correct controls, has appropriate methodology and is statistically valid, and met required revisions.

doi:10.1017/exp.2020.23.pr1

\section{Review 1: The salivary protein BPIFA2 differentially regulates sodium preference and blood pressure and in male and female mice}

Reviewer: Dr. Romana Stopková

Charles University Faculty of Science, Zoology-BIOCEV, Průmyslová 595, Vestec, Praha, Czech Republic, 12843

Date of review: 21 May 2020

Published online:

(C) The Author(s) 2020. This is an Open Access article, distributed under the terms of the Creative Commons Attribution licence (http://creativecommons.org/licenses/by/4.0/), which permits unrestricted re-use, distribution, and reproduction in any medium, provided the original work is properly cited.

Conflict of interest statement. Reviewer declares none

Comments to the Author: This short paper brings brief results on the blood pressure, heart rates and sodium preference in BPIFA2 knock-out mice compared to wild-type mice. The most interesting result is the sex-dependent effect of BPIFA2 depletion on blood pressure, i.e. males knock-out mice decrease their blood pressure whilst females knock-out increase. Authors showed that the salt preference is also sex dependent in wild-type mice whilst in knock-out mice the sex difference is no longer significant. Their claim that reduced blood pressure correlates with increased sodium preference and oppositely, increased blood pressure decrease sodium preference should be further tested because there is no statistical evidence supporting this claim. If this minor problem is explained or corrected in the MS, I find the paper acceptable as it provides new views on potential roles of this interesting protein in the regulation of the blood pressure.

\section{Score Card}

Presentation

Is the article written in clear and proper English? (30\%)

Is the data presented in the most useful manner? (40\%)

Does the paper cite relevant and related articles appropriately? (30\%)

Context 
Analysis

Are the limitations of the experiment as well as the contributions of the experiment clearly outlined? (20\%) 


\section{Review 2: The salivary protein BPIFA2 differentially regulates sodium preference and blood pressure and in male and female mice}

Reviewer: Dr. Fabio Sallustio

Date of review: 23 May 2020

Published online:

(C) The Author(s) 2020. This is an Open Access article, distributed under the terms of the Creative Commons Attribution licence (http://creativecommons.org/licenses/by/4.0/), which permits unrestricted re-use, distribution, and reproduction in any medium, provided the original work is properly cited.

Conflict of interest statement. Reviewer declares none

Comments to the Author: The article is very short. It would be more suitable as brief report in the current form. Specifically, the methods should be more detailed. Several info are missing. How many mice for each group have been analyzed? (I can deduce from figure 2: 5 for each group but it $\mathrm{n}$ must be specified in methods). How the knock out mice have been obtained? The discovery that BPIFA2 can affect blood pressure is novel and interesting but it need to be adequately discussed. In fact the discussion is too short and the description of some specific BPIFA2 functions is missing. The BPIFA2 protective role shown in the intestine should be discussed (please see: The Salivary Protein PSP / Bpifa2 Protects Against Intestinal Inflammation; The FASEB Journal 2015 29: 1_supplement). Moreover, in particular the BPIFA2 protective role at renal level must be discussed since recently BPIFA2 has been found secreted by adult renal stem/progenitor cells (please see Renal progenitor cells revert LPS-induced endothelialto-mesenchymal transition by secreting CXCL6, SAA4, and BPIFA2 antiseptic peptides; FASEB J. 2019 Oct; 33(10):10753-10766). In addition why female mice knockouts for BPIFA2 have higher blood pressure levels? In the discussion authors mention a work of menopausal women with microbiome change and hypertension condition. So how do they relate hormonal changes (during menopause) in women to BPIFA2 variation and pressure (which hormone deficiency may decompensate BPIFA2)?

\section{Score Card}

Presentation

Is the article written in clear and proper English? (30\%)

Is the data presented in the most useful manner? (40\%)

Does the paper cite relevant and related articles appropriately? (30\%)

\section{Context}

Does the abstract correctly embody the content of the article? (25\%)

Does the introduction give appropriate context? (25\%)

Is the objective of the experiment clearly defined? (25\%) 
Analysis

1.4

Does the discussion adequately interpret the results presented? (40\%)

Is the conclusion consistent with the results and discussion? (40\%)

Are the limitations of the experiment as well as the contributions of the experiment clearly outlined? (20\%) 